\title{
ANALYSIS OF SEXUAL AND REPRODUCTIVE HEALTH RISK PREFERENCES OF ZIMBABWE UNIVERSITY STUDENTS
}

\author{
Lazarus Muchabaiwa ${ }^{1,2}$ and Josue Mbonigaba ${ }^{1}$ \\ 1 Economics Department, School of Accounting, Economics and Finance, University of KwaZulu-Natal, Durban, South \\ Africa \\ 2 Economics Department, Bindura University of Science Education, Bindura, Zimbabwe
}

Corresponding author: Lazarus Muchabaiwa

Email: Imuchabaiwa@gmail.com

\begin{abstract}
Although the Zimbabwean government launched an Adolescent and Youth Sexual and Reproductive Health policy in 2010, HIV prevalence and incidence among youth remains amongst the highest in sub-Saharan Africa. Zimbabwean Youths in tertiary education institutions exhibit high-risk sexual behaviours. The study aimed to estimate the risk preference parameters of youths in a tertiary education setting to understand their risky behaviour better using prospect theory. It involved 250 students completing a socioeconomic questionnaire and making a choice from over three series of pairwise lottery questions framed around sexual and reproductive health prevention interventions. The study used bivariate techniques to examine differences in risk-taking behaviour. Ordinary least squares and interval regression techniques determined the socioeconomic determinants of the risk behaviour function. The study established an average risk aversion parameter of 0.7 and a probability weighting parameter of 0.8 . The probability weighting parameter implies that the participants were more focused on the outcomes with less concern for their likelihood. The study estimated the loss aversion parameter at 2.26, which indicates the need to reduce loss-framed messages in favour of positively framed awareness campaigns. Bivariate and multivariate regression analyses showed that income, prior sexual and reproductive health knowledge and alcoholism were associated with risk and loss aversion. We recommend positive framing of youth sexual and reproductive health awareness campaigns. We also recommend youth economic emancipation to increase economic prospects which in turn improves reference points which changes the viewing of health interventions and outcomes from the loss domain to gain domain.
\end{abstract}

Keywords: Adolescence sexual and reproductive health, Prospect theory, Risk aversion, Loss aversion

\section{INTRODUCTION}

Sexual and reproductive health risk-taking behaviour imposes morbidity and cost consequences through treatment and lost productivity ${ }^{1}$, mainly due to Sexually Transmitted Infections (STIs), including HIV/AIDS. Zimbabwe's HIV prevalence of $13.35 \%$ is one of the highest in sub-Saharan Africa3, 4 . As of 2016, 1.4 million people were HIV positive in need of treatment worth $\$ 350$ million per year ${ }^{5}$. Zimbabwe is also one of the four countries to report a high STI prevalence rate above $20 \%$ globally ${ }^{6}$.

To manage sexual and reproductive risk-taking amongst adolescents and youth, the Zimbabwean government launched its Adolescent Sexual and Reproductive Health (ASRH) policy in 20107. Notwithstanding, HIV prevalence for this age group remains high at 3\% for males and much higher for females at $5.8 \%^{2,8}$. Published literature provides insights into high-risk sexual behaviours amongst Zimbabwean youth. Musizvingoza and Wekwete ${ }^{9}$ find $27 \%$ of youth having multiple sexual partners, which is corroborated by Mzyece ${ }^{10}$, who finds high STI prevalence amongst youth at $43 \%$ for males and $57 \%$ amongst females. Further studies indicate that youth in tertiary education institutions have the highest propensity to take sexual and reproductive health risks ${ }^{11},{ }^{12}$. Furthermore, interventions to improve ASRH outcomes such as male circumcision and cervical cancer screening have low uptake. Male circumcision averages $22.9 \%^{8}$ amongst youths against a national target of $80 \%^{13}$. Only $13 \%$ of females have had cervical cancer screening ${ }^{14}$.

Male circumcision is promoted as part of the ASRH essential package because it can reduce HIV infection by $60 \%{ }^{13}$ and other STls such as human papillomavirus (HPV) by up to $82 \%{ }^{15}, 16$. HPV has a $99 \%$ chance of progressing to cervical cancer in women ${ }^{17}$. HPV infection itself has no treatment ${ }^{18}$, but the precancerous lesions that it causes are curable before they become cancers ${ }^{19}, 20$. The lesions also increase the chances of HIV infection $^{21,22}$. Research has shown that 35\% of HPV infection occurs at the onset of sexual activity ${ }^{17}$.

The continued risky sexual and reproductive behaviour of Zimbabwean youth contrasts with government efforts towards the prevention of STIs and HIV/Aids amongst young people in the country. Understanding the risk-taking of youth in sexual and reproductive health becomes imperative for the government in solving the problem of low ASRH service uptake, preventing 
new infections and future morbidity. To this effect, the purpose of this paper is to assess youth sexual and reproductive health risk preferences using prospect theory and to determine the socioeconomic determinants of the preferences to advise policy makers on how to induce youth and adolescents into utilising reproductive health services. It is thus the first study, to the best of our knowledge, to establish prospect theory parameters specific for youths in the sexual and reproductive health domain.

Prospect theory posits that people avoid risk taking when faced with choices which have uncertain positive outcomes but take risk for potentially negative outcomes relative to a reference point ${ }^{23}$. If the study data fits into prospect theory, the implication is that youth are taking risks because their minds focus on negative outcomes of ASRH interventions rather than the potentially positive outcomes. This has implications towards the framing of ASRH demand generation communications for the Zimbabwean ASRH policy.

The utility function under prospect theory incorporates probabilities of outcomes at stake, $(p, 1-p)$, and the value function $v(x)^{24}$ :

$\mathrm{PT}(x, y ; p)=\operatorname{pv}(x)+(1-p) v(y)$

(1)

where

$v(x)=\left\{\begin{array}{cc}x^{\alpha} & \text { for } x \geq 0 \\ -\lambda\left(-x^{\alpha}\right) & \text { for } x<0\end{array}\right.$

(2)

and

$$
w(p)=e^{\left[-(-\ln p)^{\gamma}\right]}
$$

$\mathrm{PT}(x, y ; p)$ is the expected prospect value over possible outcomes $(x, y)$ that have corresponding probabilities $(p, 1-p) . x^{\alpha}$ represents the gains domain for the value function and $-\lambda\left(-x^{\alpha}\right)$ represents the loss domain. The parameter $\alpha$ represents risk aversion, $\lambda$ represents the degree of loss aversion, $\gamma$ represents probability weighting. A risk aversion parameter less than 1 implies risk avoiding while higher than 1 represents risk-seeking. A positive loss aversion parameter implies loss aversion whilst a negative value implies lack of loss aversion ${ }^{24}, 25$. A probability weighting value less than 1 indicates a person who places more importance on outcomes than their likelihood ${ }^{24}$. In the ASRH context, a risk-averse person adopts safe sexual practices and consumes ASRH services that reduce chances of HIV and STI infection such as male circumcision for males ${ }^{13}$ and screening for HPV induced precancerous lesions for females ${ }^{21}$. A risk-taking youth will not bother taking up any of these ASRH services despite an active sexual life. Taking up ASRH interventions to reduce the risk of contracting HIV such as male circumcision and cervical cancer screening is consistent with loss aversion in contrast to someone who does not take any safety measures ${ }^{26}$.
The loss aversion parameter $\lambda$ in prior health domain literature ranges from 0.76 to $2.09^{27-30}$. These findings suggest that loss aversion parameters for the health domain are lower than those in the monetary field, which exceed $2^{31}$. The probability weighting parameter $\gamma$ in existing studies range from 0.25 to $1^{28,32}$. These are in line with those established by Kahneman and Tversky ${ }^{31}$, suggesting that probability weighting in the health domain lies somewhere between 0 and 1. Lim and Bruce ${ }^{30}$ found risk aversion $\alpha$ in losses and gains ranging between 0.43 and 0.93 in their weight gain or loss choice study.

Socioeconomic factors that affect risk-taking, particularly the specific risk parameters, will also be assessed in this study. Previous studies have found gender ${ }^{12}, 33-35$, financial wellbeing ${ }^{12,35}$, and lack of knowledge ${ }^{36}$ contributing to risk-taking. Risk-taking in these studies ranged from engaging in risky sexual activities or forgoing SRH beneficial interventions like cervical cancer screening, HIV testing, and condom utilisation.

\section{METHODS}

\section{Study design and sample}

The study offered 300 students a chance to participate using convenient and snowball sampling at Bindura University of Science Education in Zimbabwe. Two hundred and fifty students comprising 121 males and 129 females, completed a questionnaire which had two components. The first component sought to establish socioeconomic background characteristics of the respondents. The second component involved three series of 14 pairwise lottery tasks adapted from Tanaka, Camerer and Nguyen ${ }^{37}$. The questionnaires were pilot tested on 20 students at the same university and evaluated for any problems they might cause during actual implementation ${ }^{38}$. Study participants received a US\$5 fee to compensate for their opportunity cost of time. We only accepted students returning signed informed consent forms. We collected the data in June 2018.

\section{Lottery Choice tasks}

The study required participants to decide whether to accept a hypothetical ASRH intervention or not with the decision having a hypothetical impact on their life years from the day of decision. The hypothetical ASRH interventions offered were gender-specific such that males decided on circumcision while females had to decide on cervical cancer screening. Both options are currently ASRH interventions on offer to youth in Zimbabwe. We present the lottery choice tasks in more detail in the appendix.

\section{Ethical Considerations}

The questionnaires were approved by the University of KwaZulu Natal Human Research Ethics Institutional Review Board. 
Non-Parametric Analysis

Mathematica statistical software was used to estimate the loss aversion parameter $\lambda$ using switch points in table $A 2$ and equation 2 . The decision switch points determined values of risk aversion and the probability weighting parameter in the matrix in figure A1 which was developed by Tanaka et $\mathrm{al}^{37}$. The study applied the rank-sum test of equality of the medians of risk parameters between the two groups defined by each of the variables cited in the literature as predictors of risk-taking gender, wealth status, religious affiliation.

\section{Multivariate Analysis}

The study analysed the relationship between socioeconomic determinants and the risk aversion parameter and the loss aversion parameter using ordinary least squares and interval regression techniques, respectively.

\section{Variable definition}

The respondent's age, family monthly income and the student's monthly budget are continuous variables. The dummy variable sex takes a value of 1 for males and zero otherwise. Residence of origin takes the value one if the place of family residence is urban and zero otherwise. Early sexual debut takes the value of 1 if the respondent initiated sex before 18 years and 0 otherwise. Multiple sexual partners takes the value 1 if the student has multiple sexual partners at the same time since college enrolment and 0 otherwise. HIV test takes the value of 1 if respondent ever had an HIV test or 0 otherwise. ASRH intervention takes the value of 1 if the respondent had already undergone cervical cancer screening for females and circumcision for males in real life. Poverty takes the value of 1 if respondent's family income was less than median and 0 otherwise. Alcoholic takes values 1 if student drinks at least once a week and 0 otherwise. ASRH Knowledge takes the value of 1 if student heard any ASRH package information which consists of interventions including HIV, circumcision or cervical cancer links and 0 otherwise. Religion takes the value of 1 if student values it more important in their life decisions and 0 otherwise.

\section{RESULTS}

\section{Socioeconomic characteristics}

Table 1 shows the respondents' socioeconomic characteristics. Column 1 shows key variables, the median and frequencies are presented in column 2 whilst the interquartile range or percentages are presented in column 3. The median age of participants was 22, which is comparable to studies which used similar research participants $(37,45,46)$. The median income for the student's home was US\$700 and median family size was 5 people, while the students reported a median food and subsistence allowance of US\$100 per month. Forty-eight percent of the participants were male. Seventy percent indicated that they come from an urban background. Thirty-one percent debuted sexual activity during adolescence. Although $76 \%$ had taken an HIV test, circumcision was low for males at $19 \%$ and cervical cancer screening for females at $17 \%$. The proportion tested for HIV, circumcised, and screened for cervical cancer mirror those for the national level as presented in the 2015 Zimbabwe Demographic Health Survey (14). Respondents from households below the median income were $40 \%$, 33\% drank alcohol regularly, while $86 \%$ considered religion an important aspect of life.

Table 1: Socioeconomic characteristics

\begin{tabular}{llc}
\hline Characteristics & Median & IQR \\
\hline Age (median) & 22 & $21-22$ \\
Family monthly income (median) & $\$ 700$ & $\$ 500-\$ 1,000$ \\
Own monthly budget (median) & $\$ 100-\$ 150$ \\
Household size & 5 & $\%-6$ \\
& Frequency & $48.40 \%$ \\
Sex (male) & 121 & $70.16 \%$ \\
Residence (urban) & 174 & $30.61 \%$ \\
Early Sexual debut (adolescent sex) & 75 & $31.90 \%$ \\
Ever had more than one partners at a time since college & 74 & $76.05 \%$ \\
Ever had HIV test & 181 & $16.80 \%$ \\
Ever had Cervical cancer screening (female) & 21 & $19.13 \%$ \\
Males circumcised (male) & 22 & $39.83 \%$ \\
Poverty (less than median income) & 92 & $33.06 \%$ \\
Drinks alcohol & 82 & $85.60 \%$ \\
Religion is more important in respondent's life & 214 & 250 \\
Research participants (N) & & \\
\hline
\end{tabular}




\section{Prospect theory parameters}

The median risk aversion parameter was 0.7 IQR [0.5-1.05] which is less than 1 which means that the average student had a more risk-avoiding attitude when it comes to sexual and reproductive health. The probability weighting parameters was 0.8 IQR [0.25-0.95] which means the youths pay more attention to outcomes than their likelihood since it is less than 1 . The study found evidence of loss aversion since the estimated parameter 2.26 IQR [1.69- 3.69] was positive.

\section{Bivariate Correlation with socioeconomic variables}

The risk aversion, probability weighting and loss aversion parameters presented above were for the whole sample. To show if these parameters differ by risk-taking variable, table 2 shows differences in medians of these parameters by characteristics of the participants in the first column. Regular alcohol drinkers, youth from poor households, those who debuted sexual activity early and those with multiple sexual partners exhibited higher risk-taking. The median probability function parameter was less than one for all the variables, which suggests an inverted Sshaped value function for the average youth. This means that the participants did not put much importance on the likelihood of outcomes but were more focused on the outcomes themselves. Females showed more risk aversion tendencies than males as well as youths who delayed sexual debut. Only place of residence was associated with differences in loss aversion with youths from urban areas showing lower loss aversion than those from rural areas.

Table 2: Wilcoxon rank-sum test for equality of medians

\begin{tabular}{|c|c|c|c|}
\hline \multirow[t]{2}{*}{ Population group } & \multicolumn{3}{|l|}{ Rank sum } \\
\hline & Risk aversion $a$ & $\begin{array}{l}\text { Probability } \\
\text { function } \gamma\end{array}$ & $\begin{array}{l}\text { Loss aversion } \\
\lambda\end{array}$ \\
\hline Alcoholism: non-alcoholic & $0.6^{* * *}$ & 0.80 & 2.26 \\
\hline Alcoholic & 0.85 & 0.80 & 2.26 \\
\hline Sex: male & 0.70 & $0.85^{* *}$ & 2.26 \\
\hline female & 0.65 & 0.75 & 2.26 \\
\hline Poverty: worse off & $0.75^{* *}$ & 0.90 & 2.26 \\
\hline better off & 0.70 & $0.98^{*}$ & 2.26 \\
\hline Residence of origin: urban & 0.70 & 0.80 & $2.26^{* *}$ \\
\hline rural & 0.68 & 0.83 & 2.01 \\
\hline Religion: more important & 0.65 & 0.80 & 2.26 \\
\hline less important & 0.83 & 0.80 & 2.26 \\
\hline Early Sexual Debut: before 18 years & $0.75^{*}$ & 0.75 & 2.26 \\
\hline after 18 years & 0.65 & 0.80 & 2.26 \\
\hline Multiple Sexual Partners: no & $0.65^{* *}$ & $0.80^{* * *}$ & 2.26 \\
\hline yes & 0.98 & 0.88 & 2.26 \\
\hline
\end{tabular}

${ }^{* * *} p<0.01,{ }^{* *} p<0.05,{ }^{*} p<0.1$

\section{Multivariate correlation with socioeconomic variables}

Table 3 shows the results of multivariate regression of socioeconomic characteristics on risk aversion and loss aversion parameters for the entire group in column 1 and by gender in columns 2 and 3 . A positive coefficient means the student was more risk-taking, but a negative means less risk-taking and thus more risk-averse. Alcoholism, multiple sexual partners and poor family backgrounds were associated with high risktaking. Alcoholics had a risk-taking parameter of 0.15 units higher than non-alcoholics. Youths reporting multiple sexual partners had a risktaking parameter of 0.12 units higher than those non sexually active or those with single sexual partners at a time. Youths from a poor background had a risk-taking parameter of 0.16 units more than their better-off counterparts. Respondents with recent ASRH knowledge exposure had a risk aversion parameter 0.04 units higher than those without current ASRH information. Alcoholism had a positive correlation with risk-taking for both male and female participants while multiple sexual partnerships and poorer background had an increasing effect on risk aversion for females. Participants who had received ASRH information more recently exhibited less risk-taking, especially females. 
Table 3: Multivariate regression results on determinants of risk and loss aversion

\begin{tabular}{|c|c|c|c|c|c|c|}
\hline Variables & $\begin{array}{c}\text { (1) } \\
\text { Risk } \\
\text { aversion }\end{array}$ & $\begin{array}{c}(2) \\
\text { Male risk } \\
\text { aversion }\end{array}$ & $\begin{array}{c}(3) \\
\text { Female } \\
\text { risk } \\
\text { aversion }\end{array}$ & $\begin{array}{c}(1) \\
\text { Loss aversion }\end{array}$ & $\begin{array}{c}(2) \\
\text { Male loss } \\
\text { aversion }\end{array}$ & $\begin{array}{c}(3) \\
\text { Female loss } \\
\text { aversion }\end{array}$ \\
\hline \multirow[t]{2}{*}{ Sex } & -0.01 & & & 0.40 & & \\
\hline & $(0.05)$ & & & $(0.74)$ & & \\
\hline \multirow[t]{2}{*}{ Age } & 0.01 & 0.00 & 0.02 & 0.06 & -0.02 & 0.20 \\
\hline & $(0.01)$ & $(0.01)$ & $(0.01)$ & $(0.13)$ & $(0.15)$ & $(0.23)$ \\
\hline \multirow[t]{2}{*}{ Household size } & 0.00 & 0.03 & -0.03 & 0.01 & 0.27 & -0.20 \\
\hline & $(0.01)$ & $(0.02)$ & $(0.02)$ & $(0.19)$ & $(0.23)$ & $(0.31)$ \\
\hline \multirow[t]{2}{*}{ Alcoholic } & $0.15^{* * *}$ & $0.13^{*}$ & $0.17^{* *}$ & $1.63^{* *}$ & -0.07 & $3.58^{* * *}$ \\
\hline & $(0.05)$ & $(0.08)$ & $(0.08)$ & $(0.73)$ & $(0.88)$ & $(1.25)$ \\
\hline \multirow{2}{*}{$\begin{array}{l}\text { Early sexual } \\
\text { debut }\end{array}$} & 0.07 & 0.08 & 0.09 & 0.65 & 1.47 & -0.29 \\
\hline & $(0.06)$ & $(0.08)$ & $(0.08)$ & $(0.76)$ & $(0.93)$ & $(1.26)$ \\
\hline \multirow[t]{2}{*}{ ASRH knowledge } & $-0.04^{*}$ & -0.01 & $-0.08^{* *}$ & $-2.39^{* * *}$ & $-2.95^{* * *}$ & $-1.94^{* * *}$ \\
\hline & $(0.02)$ & $(0.03)$ & $(0.03)$ & $(0.34)$ & $(0.45)$ & $(0.51)$ \\
\hline \multirow{2}{*}{$\begin{array}{l}\text { Multiple sexual } \\
\text { partners }\end{array}$} & $0.12^{* *}$ & 0.04 & $0.23^{* *}$ & 0.89 & 0.58 & 0.61 \\
\hline & $(0.06)$ & $(0.08)$ & $(0.11)$ & $(0.82)$ & $(0.92)$ & $(1.64)$ \\
\hline \multirow{2}{*}{$\begin{array}{l}\text { ASRH } \\
\text { intervention }\end{array}$} & -0.03 & -0.03 & -0.09 & $-2.09^{* *}$ & $-3.19^{* * *}$ & -1.35 \\
\hline & $(0.06)$ & $(0.09)$ & $(0.09)$ & $(0.91)$ & $(1.15)$ & $(1.46)$ \\
\hline \multirow[t]{2}{*}{ urban residence } & -0.03 & 0.03 & -0.09 & 0.10 & 0.19 & 0.00 \\
\hline & $(0.06)$ & $(0.08)$ & $(0.08)$ & $(0.78)$ & $(0.96)$ & $(1.21)$ \\
\hline \multirow{2}{*}{$\begin{array}{l}\text { Religion } \\
\text { importance }\end{array}$} & 0.01 & 0.01 & 0.03 & $-1.58^{*}$ & $-2.04^{*}$ & 0.03 \\
\hline & $(0.07)$ & $(0.09)$ & $(0.12)$ & $(0.95)$ & $(1.05)$ & $(1.87)$ \\
\hline \multirow[t]{2}{*}{$\begin{array}{l}\text { Poverty } \\
\text { background }\end{array}$} & $0.16^{* * *}$ & 0.09 & $0.20^{* *}$ & $1.39^{*}$ & 1.01 & 1.15 \\
\hline & $(0.05)$ & $(0.08)$ & $(0.08)$ & $(0.73)$ & $(0.89)$ & $(1.21)$ \\
\hline R-squared & 0.14 & 0.09 & 0.31 & & & \\
\hline
\end{tabular}

Standard errors in parentheses, ${ }^{* * *} p<0.01,{ }^{* *} p<0.05,{ }^{*} p<0.1$

For the loss aversion estimates, a positive sign implies less aversion of losses while a negative sign implies more loss aversion. Alcoholism and poverty were associated with less aversion of health losses. Alcoholics had a loss aversion parameter 1.63 units less than non-alcoholics. Poor youths had a loss aversion parameter 1.39 units lower than non-alcoholics. ASRH knowledge, having accepted the ASRH intervention in real life and religiosity were associated with higher loss aversion. Respondents with recent ASRH knowledge exposure had a loss aversion parameter 2.39 units higher than those without recent ASRH information. Youth who accepted ASRH intervention in real-life exhibited a loss aversion parameter 2.09 units higher while for more religious youths, it was 1.58 units higher. Sub analysis by gender shows that females who took beer more often had 3.58 units lower loss aversion. ASRH knowledge was associated with 2.95 more units and 1.94 more units of loss aversion for both male and female participants, respectively. Having accepted the ASRH intervention and religiosity were associated with 3.19 more units and 2.04 more units of loss aversion among males.

\section{DISCUSSION}

Despite the government's efforts to improve adolescent and youth sexual and reproductive health through the ASRH policy, Zimbabwean youth continue risky sexual behaviour leading to poor ASRH outcomes $2,8,9,13,14$. To better understand the risk-taking of the Zimbabwean youth, this study sought out to establish sexual and reproductive health risk preference parameters of youths in a tertiary education setting and their determinants.

The study found average risk preference parameters for risk aversion $a$ and $\gamma$ of 0.7 and 0.8 less than one. These findings imply that the average youth is risk-averse and is more concerned by ASRH outcomes than the likelihood of their occurrence. The overall loss aversion parameter was 2.26, which suggests that the 
average youth is loss averse. These findings are consistent with prospect theory parameters established in prior studies ${ }^{24,31,37,39,40}$. Parameter estimates in current literature range 0.11 to 1.24 for risk aversion, 0.13 to 1 for probability weighting and 0.42 to 3.47 for loss aversion. The fitting of these parameters within existing literature implies that prospect theory framework is fit for analysing risk-taking for the health domain as argued by Attema ${ }^{41}$.

The second significant finding of the study relates to socioeconomic determinants of the risk parameters. The study found risk aversion and loss aversion lower for alcoholics, the poor, early sexual debutants and youth with multiple sexual partners. On the other hand, ASRH knowledge and religiosity significantly promoted risk aversion and loss aversion. These risk factors are similar to those found in recent literature. Francis recently found alcohol increasing risky sexual behaviour amongst youth in South Africa ${ }^{42}$ but religiosity having mitigating effects. Poverty has also been found influencing risk-taking amongst youths ${ }^{43}$. Multiple sexual partners led to high risk sexual and reproductive health in Ghana ${ }^{44}$.

These findings have several practical implications. Firstly, the result of an association between ASRH knowledge and risk and loss aversion implies scope of ASRH information awareness for youth to promote risk aversion. In addition to that, the finding that youth-focused more on outcomes than probabilities means that the ASRH information campaigns should focus on outcomes instead of their likelihood. Furthermore, the fitting of the research findings in prospect theory predictions means that ASRH information campaigns have to focus on positively framed messages about interventions such as circumcision, cervical cancer screening, HIV testing and contraceptives use. This way, they can promote risk aversion, which is predicted for the positive domain while not conditioning the minds of the youths for the loss domain for which they would be risk-taking ${ }^{31}$.

Regarding the reference point, Zimbabwe as a country is undergoing a challenging economic environment. The formal unemployment rate has been above $85 \%$ for over a decade, which presents gloomy economic prospects for youth, even in higher education ${ }^{45}$. Prospect theory thus predicts that most of the Zimbabwean youths perceive their current economic status in the loss domain. McDermott ${ }^{46}$ suggests the design of effective intervention programs that can push youths into the gain domain. A revival of the Zimbabwean economy, such as reindustrialisation and better wages, can improve prospects of a better life and move youths from the loss domain into the gain domain. Providing youths with loans to start their businesses is also an alternative given that their families can hardly raise finances required for sustainable start-ups.
This study used male circumcision and cervical cancer screening for females. For policy-making purposes, this study is necessary as it produced preferences of the relevant population which can be used to improve utility and to reduce disutility in these procedures. Male circumcision reduces the chances of contracting STIs by $60 \%{ }^{47}$. Concerns that have been noted in male circumcision which affect utility, including fear of pain, fear of HIV testing which is compulsory before circumcision, indirect costs such as transport and lack of comfort with female medical staff 48,49 . There have also been rare cases were circumcision was not successfully done and ended up affecting the patient $\mathrm{t}^{48,49}$. It appears these cases, as rare as they are, may shape youths perception about the safety of the procedure. For cervical cancer screening, women have been found afraid or psychologically not comfortable with medical examination, tests, procedures, or those who conduct them ${ }^{50}$. They could thus put more weight in the expected psychological losses than the gains they could possibly get from early cancer detection. The parameters established in this study which confirms prospect theory predictions thus suggest the need to make ASRH services more comfortable for youths in a friendly environment to reduce fear.

The study was conducted at one institution, which limited geographical coverage of youths participating in the study. Although the use of university students in prospect theory risk preference research is common, the parameters established in such environments might not be generalised beyond the study setting. Future studies with better funding could be expanded to cover a wider population. Future studies could investigate other SRH interventions as well as investigating the effects of ASRH message framing.

\section{CONCLUSION}

The study concludes that youth sexual and reproductive health risk can be explained by prospect theory. Policymakers should focus on positively framed awareness campaigns to improve the utilisation of ASRH services and reduce risky behaviour. On average, youth are more sensitive to positively framed outcomes and less so about the probabilities of uncertain outcomes occurring. There is also a need to design different strategies for youth as risk aversion and loss aversion differs by income status, prior sexual experience and current ASRH knowledge.

\section{Conflict of interest}

The authors declare no potential conflict of interest.

\section{REFERENCES}

1. Lawless L, Drichoutis AC, Nayga RM. Time preferences and health 
behaviour: a review. Agricultural and Food Economics. 2013; 1(1):17.

2. Gonese E, Musuka G, Ruangtragool L, et al. Comparison Of HIV Incidence In The Zimbabwe Population-Based HIV Impact Assessment Survey (20152016), With Modeled Estimates: Progress Toward Epidemic Control. AIDS Research and Human Retroviruses. 2020; (ja).

3. Blower S, Okano JT. Precision public health and HIV in Africa. The Lancet Infectious Diseases. 2019; 19(10):1050-2.

4. Bulstra CA, Hontelez JA, Giardina F, et al. Mapping and characterising areas with high levels of HIV transmission in sub-Saharan Africa: A geospatial analysis of national survey data. PLoS medicine. 2020; 17(3):e1003042.

5. Zimbabwe Go. Zimbabwe national HIV and AIDS strategic plan III (ZNASP), 2015-2018: Commitment towards fast tracking 90.90 .90 targets by 2020 and ending AIDS by 2030.: National AIDS Council of Zimbabwe; 2015.

6. WHO. Report on global sexually transmitted infection surveillance 2018. World Health Organization; 2018. Report No.: 9241565691.

7. Blum RW, Mmari K, Alfonso NY, et al. ASRH Strategic Plan Review. Johns Hopkins School of Public Health; 2015.

8. (MOHCC) MoHaCC. Zimbabwe Population-Based HIV Impact Assessment (ZIMPHIA) 2015-16: First Report. Harare: MOHCC; 2017 July 2017.

9. Musizvingoza R, Wekwete NN. Factors facilitating risky sexual behaviour among youths in Mufakose, Harare, Zimbabwe. African Population Studies. 2018; 32(1).

10. Busisiwe M. Factors associated with sexually transmitted infections among youths in Umguza district [Masters Thesis]. Harare: University of Zimbabwe; 2014.

11. Akande A. AIDS-related beliefs and behaviours of students: evidence from two countries (Zimbabwe and Nigeria). International Journal of Adolescence and Youth. 1994; 4(34):285-303.
12. Shumba A, Mapfumo J, Chademana J. The Prevalence of Concurrent Sexual Partnerships among Students in Institutions of Higher Education in Zimbabwe. Journal of Human Ecology. 2011; 34(1):53-65.

13. McGillen JB, Stover J, Klein DJ, et al. The emerging health impact of voluntary medical male circumcision in Zimbabwe: An evaluation using three epidemiological models. PloS one. 2018; 13(7):e0199453-e.

14. ZIMSTAT, ICFI. Zimbabwe Demographic and Health Survey 2015: Final Report. Rockville, Maryland, USA: Zimbabwe National Statistics Agency (ZIMSTAT) and ICF International.

15. Morris BJ, Hankins CA. Effect of male circumcision on risk of sexually transmitted infections and cervical cancer in women. The Lancet Global Health. 2017; 5(11):e1054-e5.

16. Morris BJ, Hankins CA, Banerjee J, et al. Does Male Circumcision Reduce Women's Risk of Sexually Transmitted Infections, Cervical Cancer, and Associated Conditions? Front Public Health. 2019; 7:4-.

17. Kuguyo O, Matimba A, Tsikai N, et al. Cervical cancer in Zimbabwe: a situation analysis. Pan Afr Med J. 2017; 27:215-.

18. CDC. Human Papillomavirus (HPV)Treatment and Care: Centers for Disease Control and Prevention; 2016 [Available from: https: / /www.cdc.gov/std/hpv/treat ment.htm.

19. WHO. Human papillomavirus (HPV) and cervical cancer: World Health Organization; 2019 [updated 24 January 2019. Available from: https://www.who.int/newsroom/fact-sheets/detail/humanpapillomavirus-(hpv)-and-cervicalcancer.

20. Gabaza C, Chonzi P, Chadambuka A, et al. Utilization and outcomes of cervical cancer screening services in Harare City, 2012-2016: a secondary data analysis. BMC health services research. 2019; 19(1):454.

21. Looker KJ, Rönn MM, Brock PM, et al. Evidence of synergistic relationships between HIV and Human 
Papillomavirus (HPV): systematic reviews and meta-analyses of longitudinal studies of HPV acquisition and clearance by HIV status, and of HIV acquisition by HPV status. Journal of the international AIDS Society. 2018; 21(6):e25110.

22. Averbach SH, Gravitt PE, Nowak RG, et al. The association between cervical HPV infection and HIV acquisition among women in Zimbabwe. AIDS (London, England). 2010; 24(7):1035.

23. Bendor J. Bounded rationality. In: Smelser NJ, Baltes B, editors. International Encyclopedia of the Social and Behavioral Sciences 2001. p. 1303--7.

24. Nguyen Q, Leung P. Do fishermen have different attitudes toward risk? An application of prospect theory to the study of Vietnamese fishermen. Journal of Agricultural and Resource Economics. 2009:518-38.

25. Abdellaoui M, Bleichrodt $\mathrm{H}$, Paraschiv C. Loss aversion under prospect theory: A parameter-free measurement. Management Science. 2007; 53(10):1659-74.

26. Writing Group for C-C, Simianu VV, Grounds MA, et al. Understanding clinical and non-clinical decisions under uncertainty: a scenario-based survey. BMC Med Inform Decis Mak. 2016; 16(1):153-.

27. Abellan-Perpinan JM, Bleichrodt $H$, Pinto-Prades JL. The predictive validity of prospect theory versus expected utility in health utility measurement. Journal of Health Economics. 2009; 28(6):1039-47.

28. Bleichrodt $H$, Abellan-Perpiñan JM, Pinto-Prades $\mathrm{JL}$, et al. Resolving inconsistencies in utility measurement under risk: Tests of generalizations of expected utility. Management Science. 2007; 53(3):469-82.

29. Attema AE, Brouwer WB, l'Haridon O, et al. An elicitation of utility for quality of life under prospect theory. Journal of health economics. 2016; 48:121-34.

30. Lim S-L, Bruce AS. Prospect theory and body mass: characterizing psychological parameters for weight- related risk attitudes and weight-gain aversion. Frontiers in psychology. 2015; 6:330.

31. Tversky A, Kahneman D. Advances in prospect theory: Cumulative representation of uncertainty. Journal of Risk and uncertainty. 1992; 5(4):297-323.

32. Bleichrodt H, Pinto JL. A parameterfree elicitation of the probability weighting function in medical decision analysis. Management science. 2000; 46(11):1485-96.

33. Nkomazana N, Maharaj P. Perception of risk of HIV infections and sexual behaviour of the sexually active university students in Zimbabwe. SAHARA-J: Journal of Social Aspects of HIV/AIDS. 2014; 11(1):42-50.

34. Gwede CK, McDermott RJ, Westhoff WW, et al. Health Risk Behavior of Rural Secondary School Students in Zimbabwe. Health Education \& Behavior. 2001; 28(5):608-23.

35. Mapfumo J, Shumba A, Zvimba R, et al. Sexual Activity and Prevalence of Multiple Sexual Relationships among Female Students at a University Campus in Zimbabwe. The Anthropologist. 2012; 14(5):383-91.

36. Jia Y, Li S, Yang R, et al. Knowledge about cervical cancer and barriers of screening program among women in Wufeng County, a high-incidence region of cervical cancer in China. PloS one. 2013; 8(7):e67005.

37. Tanaka T, Camerer CF, Nguyen Q. Risk and time preferences: Linking experimental and household survey data from Vietnam. American Economic Review. 2010; 100(1):55771.

38. Presser S, Couper MP, Lessler JT, et al. Methods for testing and evaluating survey questions. Public opinion quarterly. 2004; 68(1):109-30.

39. Tversky A, Kahneman D. Prospect theory: an analysis of decision under risk. Econometrica. 1979; 47(2):26392.

40. Lobel RE, Klotzle MC, Silva PVJDG, et al. Prospect theory: a parametric analysis of functional forms in Brazil. Revista de Administração de Empresas. 2017; 57(5):495-509. 
41. Attema AE, Brouwer WB, l'Haridon O. Prospect theory in the health domain: A quantitative assessment. Journal of health economics. 2013; 32(6):105765.

42. Francis JM, Myers B, Nkosi S, et al. The prevalence of religiosity and association between religiosity and alcohol use, other drug use, and risky sexual behaviours among grade 8-10 learners in Western Cape, South Africa. Plos one. 2019; 14(2):e0211322.

43. Orihuela CA, Mrug S, Davies S, et al. Neighborhood Disorder, Family Functioning, and Risky Sexual Behaviors in Adolescence. Journal of Youth and Adolescence. 2020:1-14.

44. Ganle JK, Amoako D, Baatiema L, et al. Risky sexual behaviour and contraceptive use in contexts of displacement: insights from a crosssectional survey of female adolescent refugees in Ghana. International journal for equity in health. 2019; 18(1):127.

45. Rusvingo SL. The Zimbabwe soaring unemployment rate of $85 \%$ : A ticking time bomb not only for Zimbabwe but the entire SADC region (2014). Global Journal of Management and Business Research. 2015.
46. McDermott R. Adolescent HIV prevention and intervention: A prospect theory analysis. Psychology, Health \& Medicine. 1998; 3(4):37185.

47. Hallett TB, Singh K, Smith JA, et al. Understanding the Impact of Male Circumcision Interventions on the Spread of HIV in Southern Africa. PLOS ONE. 2008; 3(5):e2212.

48. Skolnik L, Tsui S, Ashengo TA, et al. A cross-sectional study describing motivations and barriers to voluntary medical male circumcision in Lesotho. BMC public health. 2014; 14(1):1119.

49. George G, Strauss M, Chirawu P, et al. Barriers and facilitators to the uptake of voluntary medical male circumcision (VMMC) among adolescent boys in KwaZulu-Natal, South Africa. African Journal of AIDS Research. 2014; 13(2):179-87.

50. Ackerson K, Preston SD. A decision theory perspective on why women do or do not decide to have cancer screening: systematic review. Journal of advanced nursing. 2009; 65(6):1130-40. 